\title{
Migración internacional y transiciones a la adultez en México
}

\section{María de Jesús Ávila-Sánchez, José Alfredo Jáuregui-Díaz y Karina Pizarro-Hernández}

\author{
Universidad Autónoma de Nuevo León, México/ \\ Universidad Autónoma del Estado de Hidalgo, México
}

Resumen

En esta investigación se estudia el proceso de transición a la edad adulta de los jóvenes mexicanos con experiencia migratoria en Estados Unidos y el efecto que tuvo este desplazamiento en cinco eventos transicionales empleando modelos de historia de evento de tiempo continuo — event history analysis - utilizando para su elaboración como fuente de información primaria la Encuesta Nacional de la Juventud del año 2010. También se analizan la interrelación entre los diferentes eventos transicionales comparando al grupo de estudio con los jóvenes sin experiencia migratoria internacional en diferentes contextos. Los resultados ponen de manifiesto que la experiencia migratoria tiene un efecto en el calendario y la intensidad de las diversas transiciones hacia la adultez. La migración agrega complejidad y altera el curso de vida de los jóvenes mexicano, limitando el bienestar y desarrollo sustentable de su proyecto futuro de vida.

Palabras clave: Jóvenes, migración, internacionales, transiciones, adultez.

Abstract

\section{International migration and transitions to adulthood in Mexico}

This research studies the process of transition to adulthood of young Mexicans with migratory experience in the United State and the effect that this displacement had on five transitional events using event history models of continuous time - history history analysis-, using for its elaboration as primary source of information the National Survey of the Youth of the year 2010. The interrelationship between the different transitional events is also analyzed, comparing the study group with the young without international migration experience in different contexts. The results show that migration experience has an effect on the timing and intensity of the various transitions into adulthood. Migration adds complexity and alter the course of life of young Mexican, limiting the well-being and sustainable development of their future life project.

Key words: Youth, migration, international, transitions, adulthood. 


\section{INTRODUCCIÓN}

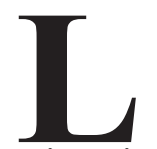

a experiencia migratoria a Estados Unidos entre los jóvenes mexicanos es un evento significativo en su vida que facilita su transición a papeles económicos adultos, la relación entre migración y juventud no se limita a que ambos eventos tienen lugar en el mismo tramo etario, ni a las situaciones estructurales y culturales que impulsan la migración en la juventud, sino a los efectos que la experiencia migratoria tiene en el curso de vida.

La migración es una estrategia económica importante que jóvenes hombres y mujeres emplean para alcanzar objetivos determinados como, el acceso a un empleo bien remunerado, la búsqueda de autonomía económica, la acumulación de poder adquisitivo, la formación de una familia, entre otros. Sin embargo, las diferencias sociales y económicas dan matices específicos a la transición de los jóvenes migrantes, por lo que su examen será de fundamental importancia.

La experiencia migratoria pudiera generar efectos contradictorios en el curso de vida, al convertirse en un catalizador para adelantar o retrasar algunos eventos. Entonces, ¿cuál es el efecto de la experiencia migratoria en la primera relación sexual, el primer matrimonio, la salida de la escuela, la entrada al mercado de trabajo y el nacimiento del primer hijo?

Para ello, se situó la experiencia migratoria a Estados Unidos en relación con otras transiciones de los jóvenes, cuyos efectos pueden ser múltiples y estar interrelacionados, debido a que varios eventos transicionales pueden ocurrir de manera simultánea, siendo difícil separar el efecto de la migración en un solo evento sin considerar colectivamente a los otros eventos transicionales.

El objetivo de este trabajo es analizar el proceso de transición de los jóvenes con experiencia migratoria a Estados Unidos a la edad adulta en México, así como probar si la experiencia migratoria particular tiene un efecto en el comportamiento de los eventos transicionales característicos del paso a la vida adulta o si su influencia puede variar de acuerdo con otras características socioeconómicas individuales. Para su elaboración se emplean los microdatos de la Encuesta Nacional de la Juventud del año 2010 (ENJ 2010).

Se comparan el calendario y la intensidad de los eventos tales como: la primera relación sexual, el primer matrimonio o unión en pareja, la primera maternidad o paternidad, la salida de la escuela y la entrada al trabajo, 
todo esto entre los jóvenes con experiencia migratoria a Estados Unidos y no migrantes. Asimismo, se analiza la interrelación entre los eventos transicionales con las desigualdades de cohorte generacional, sexo y estrato social que puedan acelerar o retardar su ocurrencia, asignándole matices específicos a esa transición.

De manera esquemática la investigación se divide en cuatro apartados, en el primero se aborda la interconexión entre la migración y los marcadores de la transición a la adultez; el segundo trata sobre la metodología empleada para su elaboración, de manera que se presentan las características de la Encuesta Nacional de la Juventud y el método estadístico Event history analysis; en el tercero se abordan los resultados descriptivos del análisis y después los modelos estadísticos para determinar el efecto de la migración en los cinco eventos transicionales familiares y reproductivos que se examinan en este trabajo; en el cuarto, a modo de conclusión, se realiza una reflexión de los principales hallazgos, para finalizar se enuncia la bibliografía empleada.

\section{LA INTERCONEXIÓN ENTRE LA MIGRACIÓN Y LOS MARCADORES DE LA TRANSICIÓN A LA ADULTEZ}

El desarrollo de la sociedad moderna propició el surgimiento de la condición social de la juventud, como un actor histórico y como símbolo cultural, a lo que Hobsbawm (2001) define como la "juvenilización" de la sociedad occidental. En este sentido Beck señala que:

el Estado de bienestar que se implementó al finalizar la Segunda Guerra Mundial activó un nuevo proceso de individualización que impulsaría lo que se define como un proceso de destradicionalización de los modos de vida de la sociedad industrial (Beck, 1998).

La nueva realidad que señala Beck, se caracteriza por el cambio de una biografía vez más des-normalizada, des-institucionalizada, individualizada y reversible (Macmilla, 2005) por lo que se ha vuelto menos convencional, modelada y predecible (Konietzka y Huinink, 2003), por otra de elección, en donde los jóvenes se ven abocados a tomar decisiones y optar a elegir, dependiendo de los capitales heredados o acumulados (Bourdieu, 1997).

Se trata de nuevas formas de construcción biográfica y proyección de futuro de las actuales generaciones, propios de un tiempo que exige de los jóvenes un papel activo que va ajustándose en su empeño de sobrevivir en las condiciones de vida que les ha tocado vivir, caracterizado por una realidad socioeconómica y laboral donde la incertidumbre, la flexibilidad y 
adaptación son una constante, en lugar de las certidumbres y seguridad que les brindaba el modelo de emancipación de sus padres y tránsito a la vida adulta de las sociedades industrializadas (Montiel, 2009).

Las migraciones juveniles están fuertemente imbricadas en este proceso de cambio y transformación social, ya que cada vez son más los jóvenes que migran en busca de oportunidades laborales, educativas o de estilo de vida y de consumo, enfrentando los desafíos que presenta la movilidad internacional durante la transición hacia la adultez.

La perspectiva del curso de vida combinada con el criterio etario, resulta una herramienta fructífera para examinar el efecto de la migración en el calendario y la intensidad de los eventos transicionales reproductivos y familiares de los jóvenes, claves en el desempeño de sus roles de adulto, que además dan forma a los cambios demográficos en la sociedad.

\section{La transición a la adultez y la migración}

Los patrones de movilidad espacial de los individuos también se han vuelto más complejos con el tiempo, así la migración es vista como un evento que permite la continuidad en la trayectoria prevista, migrar para continuar con los estudios, para asumir roles de la vida adulta, insertarse en el mercado de trabajo o para formar una familia (Ariza, 2005).

El estudio de la interconexión entre la migración y la transición a la adultez es difícil por lo que ha sido poco explorada en la literatura internacional y de México. Debido a los problemas metodológicos que incluyen la falta de datos adecuados o suficientes, la dependencia de encuestas transversales (Mussino y Strozza, 2012), las dificultades asociadas a la aplicación de medidas demográficas para una población móvil (Parrado, 2011) y la falta de un marco conceptual que defina los conceptos básicos (Wilson y Sigle-Rushton, 2014), entre otros.

No obstante, existe una serie de estudios sobre el efecto de la migración en alguno de los eventos de la transición, por ejemplo en:

- La primera relación sexual (Mberu y White, 2011; Anglewicz, Van Landingham y Pahuengsmran, 2014).

- El primer matrimonio o unión en pareja (Parrado, 1998 y 2011; Jampiklay, 2006; Chattopadhyay, 1999; Kendel y Massey, 2002; Fan y Huang, 1998; Lindstrom y Giorguli, 2007 y Pérez Amador, 2008).

- La primera maternidad y paternidad (Parrado, 2011; Wilson y SigleRushton, 2014). 


\section{Migración internacional y transiciones a la adultez en México / M. de J. ÁVILA SÁNCHEZ et al.}

Mientras que el efecto de la migración en el conjunto de los cinco eventos transicionales referidos se ha examinado poco, pese a que algunos autores han señalado que estos eventos no son necesariamente independientes, es decir, que un evento puede influir en el desarrollo de los otros, es por ello que está investigación se decidió examinar la experiencia migratoria en conjunto con otras transiciones de los jóvenes, cuyos efectos pueden ser múltiples y estar interrecionados, debido a que varios eventos transicionales pueden ocurrir de manera simultánea.

La migración de los jóvenes manifiestan, también, condiciones macroestructurales, como las desigualdades por cohorte generacional, sexo y estrato social que actúan en el ámbito microsocial, tanto a nivel individual como de familia, y que pueden acelerar o retardar la ocurrencia de los eventos transicionales (Hogan y Astone, 1986; Mora y Oliveira, 2008).

La literatura de investigación sobre la migración ha comprobado suficientemente la selectividad de los migrantes, esto nos lleva a plantear la hipótesis de que los jóvenes migrantes son un grupo especial de personas cuyo proceso de transición de la juventud a la vida adulta es diferentes en comparación con los jóvenes no migrantes en cuanto a la ocurrencia o ausencia de eventos que desde una perspectiva de curso de vida forman parte de la transición a la vida adulta.

En la literatura sobre México se ha comprobado empíricamente que existe una serie de desigualdades sociales y económicas que tiene un efecto tempo $^{21}$ en la ocurrencia de los eventos que conforman el proceso de transición a la vida adulta (Echarri y Pérez, 2004; Mier y Terán, 2004; Coubés y Zenteno, 2005; Araiza, 2005; Gandini y Castro, 2006; Oliveira, 2006; Mora y Oliveira, 2008; Ávila y Jáuregui, 2014).

La experiencia migratoria es considerada un factor perturbador en el proceso de transición a la adultez en los jóvenes mexicanos. La migración se entiende no sólo como el cruce de un límite administrativo sino como un proceso que implica una sucesión de contactos socioculturales con permean todas las áreas de su vida. El migrante constantemente se encuentra enfrentando sus valores y tradiciones con los de la cultura del país de destino, lo que le obliga hacer concesiones dando lugar a una confusión identitarias, lo que puede afectar de manera compleja su comportamiento, actitudes y decisiones sobre la iniciación sexual, la emancipación residencia, la adopción de roles conyugales o parentales. En este sentido Ariza (2005: 177) considera "la migración como un evento en el curso de vida... que otorga sentido a la historia de vida individual".

\footnotetext{
${ }^{21}$ Se refiere a la rapidez o velocidad de movimiento.
} 


\section{Metodología}

La investigación planteada fue realizada usando los microdatos de la ENJ2010, que incluye una batería de preguntas retrospectivas sobre la actividad sexual, el matrimonio, la fecundidad, el primer trabajo y la salida de la escuela, a partir de la cual se puede determinar la edad al momento de la iniciación sexual, el primer matrimonio o unión en pareja, el nacimiento del primer hijo, la finalización de la educación formal, la entrada al mercado laboral y la experiencia migratoria. Una limitación de la encuesta es que captura información transversal sobre el estado actual de los jóvenes, por lo tanto, los datos están limitados en cuanto al calendario de los eventos.

El conjunto de los jóvenes de 15 a 29 años de edad se dividió en dos subgrupos, al primero se le denomina migrantes y están referidos a quienes tienen experiencia migratoria a Estados Unidos, el segundo está compuesto por jóvenes sin experiencia migratoria. Ambos subgrupos son identificables en la ENJ2010. Para definir a los jóvenes migrantes se seleccionaron a aquellos jóvenes que en los últimos cinco años, entre el 2005 y 2010, hubieran realizado por lo menos una migración a Estados Unidos.

Además, como se parte del supuesto que la estructura social y económica es determinante en las transiciones de los jóvenes migrantes, se analizaron en esta población dos cohortes generacionales, 1981-1986 y 1987$1998^{22}$, el sexo (como una aproximación al género), el tipo de localidad de residencia (localidad urbana y no urbana) ${ }^{23}$, región donde reside el joven al momento de la encuesta (región tradicional de migración y resto del país) ${ }^{24}$ y el estrato socioeconómico de origen (muy bajo-bajo y medio-alto).

La variable de estrato socioeconómico fue construida agrupando tres índices: el primero sobre calidad de la vivienda, el segundo relacionado con el tipo de actividad económica y el tercero sobre la escolaridad de los miembros del hogar. ${ }^{25}$ Está referida al momento de la encuesta, ya que por

${ }^{22}$ Los jóvenes que componen la primera cohorte son los que nacieron entre 1987 y 1998 y tenían al momento de la encuesta entre 18 y 23 años, y los de la segunda nacieron entre 1981 y 1986 y tenían entre 24 y 29 años de edad.

${ }^{23}$ Se consideraron localidades urbanas las que tenían más de 15 mil habitantes, mientras que las no urbanas se definieron como aquellas con menos de 15 mil personas

${ }^{24}$ CONAPO ha establecido una regionalización de los lugares de origen, donde articula criterios geográficos y migratorios y subdivide al territorio mexicano en cuatro regiones: Tradicional, Norte, Centro y Sur-sureste.

${ }^{25}$ La variable fue elaborada por el Dr. Carlos Echarri sobre la base de tres índices:

a. Calidad de la vivienda, se construyó a partir de las variables de tamaño del hogar, materiales de los pisos, cocina exclusiva para cocinar, agua entubada, excusado dentro de la vivienda, drenaje, luz eléctrica y hacinamiento ( 2.5 personas por dormitorio).

b. Escolaridad media relativa de todos los miembros del hogar, se elaboró a partir de un indicador compuesto por la escolaridad acumulada según sexo y edad y por la escolaridad relativa por edad y sexo. 
las características del instrumento se carece de información al momento de ocurrencia del evento.

Después de eliminar los casos sobre los que no se disponía de información válida, la muestra de los jóvenes migrantes quedó conformada por 441 individuos, de los cuales 128 eran mujeres y 313 hombres. En la Tabla 1 se muestra el número casos de jóvenes migrantes que han experimentado cada transición según las cinco variables empleadas en esta investigación: el sexo, la cohorte de nacimiento, tipo de localidad de residencia, estrato social y región en donde reside.

Tabla 1: Número casos de jóvenes migrantes que han experimentado la ocurrencia de los eventos del curso de vida en el tránsito a la adultez de acuerdo con las dimensiones de análisis, 2010

\begin{tabular}{|c|c|c|c|c|c|c|}
\hline $\begin{array}{l}\text { Categorías } \\
\text { /Evento }\end{array}$ & $\begin{array}{r}\text { Salida de la } \\
\text { escuela }\end{array}$ & $\begin{array}{r}\text { Primera } \\
\text { relación sexual }\end{array}$ & $\begin{array}{r}\text { Primer } \\
\text { matrimonio }\end{array}$ & $\begin{array}{r}\text { Primer } \\
\text { nacimiento }\end{array}$ & $\begin{array}{r}\text { Salida del } \\
\text { trabajo }\end{array}$ & Total \\
\hline \multicolumn{7}{|l|}{ Sexo } \\
\hline Mujeres & 105 & 100 & 81 & 65 & 105 & 128 \\
\hline Hombres & 258 & 277 & 154 & 109 & 300 & 313 \\
\hline \multicolumn{7}{|l|}{ Cohorte } \\
\hline 1995-1998 & 125 & 128 & 65 & 41 & 152 & 175 \\
\hline 1981-1986 & 238 & 249 & 170 & 133 & 253 & 266 \\
\hline \multicolumn{7}{|c|}{ Tipo de localidad } \\
\hline Urbano & 199 & 216 & 127 & 90 & 235 & 248 \\
\hline No Urbano & 164 & 161 & 108 & 84 & 170 & 193 \\
\hline \multicolumn{7}{|c|}{ Estrato socioeconómico } \\
\hline Muy Bajo-Bajo & 307 & 189 & 133 & 101 & 201 & 223 \\
\hline Medio-Alto & 172 & 188 & 102 & 73 & 206 & 218 \\
\hline \multicolumn{7}{|l|}{ Región } \\
\hline Tradicional & 133 & 137 & 91 & 72 & 138 & 154 \\
\hline Resto & 230 & 240 & 144 & 102 & 267 & 287 \\
\hline
\end{tabular}

\section{Análisis de la información}

En primera instancia se realizó un análisis descriptivo de los cinco eventos referidos y en segundo lugar se emplearon modelos de historia de evento

c. Ocupación mejor remunerada de los miembros del hogar, se seleccionó la actividad de mayor remuneración por hogar, después se agruparon las actividades económicas en 12 categorías: estudiante, trabajador sin pago, buscador de empleo, quehaceres del hogar, incapacitado, no trabaja, jornalero o peón, trabajador a destajo, cuenta propia, jubilado o pensionado, empleado u obrero y patrón o empresario. 
de tiempo continuo-event history analysis—, una técnica estadística que permite el uso de variables fijas y variables en el tiempo y no requiere de supuestos de proporcionalidad (Allison, 1982).

Se considera como unidad de análisis el año/persona, ya que las respuestas a la duración de los eventos es en años, esta aproximación garantiza los estimadores apropiados de los errores estándar y las pruebas de significatividad (Petersen, 1991).

En particular se elaboraron tablas de vida para comparar la intensidad y calendario de los eventos transicionales de los jóvenes según su condición migratoria, también se aplicaron los tests de Log-Rank y Wilcoxon (Breslow) para determinar si había una diferencia significativa $(\mathrm{p}<0.05)$ entre las curvas de supervivencia (Hosmer, Lemeshow and May, 1999).

Las variables consideradas al analizar el proceso de transición de los jóvenes con experiencia migratoria a Estados Unidos a la vida adulta se definido por cinco eventos: iniciación sexual, inicio de la vida reproductiva, formación de pareja, salida del sistema educativo, entrada al mercado de trabajo, los cuales son referidos en la literatura (Hogan y Astone, 1986). La ENJ2010 proporciona información sobre la edad a la cual cada persona experimentó esas transiciones.

\section{Resultados}

La mayoría de los jóvenes con experiencia migratoria en Estados Unidos ya han realizado tres transiciones: entrar al mercado de trabajo, tener la primera relación sexual y finalizar su instrucción escolar. Así, ocho de cada diez habían experimentado su primera relación sexual y habían concluido su educación formal, y nueve de cada diez habían entrado al mercado laboral (Tabla 2) como ya había sido señalado por Echarri y Pérez Amador (2004).

La unión en pareja es la tercera transición en prevalencia, un poco más de la mitad de los jóvenes migrantes ya habían experimentado el matrimonio en el momento de la encuesta. El nacimiento del primer hijo(a) fue la transición menos experimentada, solo alrededor de un tercio de los jóvenes migrantes la habían experimentado.

Los patrones de transición a la edad adulta difieren según su condición migratoria. La proporción de jóvenes migrantes que ya había experimentado su primera relación sexual al momento de la encuesta es 24 puntos porcentuales superior a los no migrantes, para el primer empleo, la finalización de la educación formal y la primera unión en pareja esta proporción es alrededor de 20 puntos porcentuales en comparación con los no migrantes. 
Tabla 2: Porcentaje de jóvenes migrantes y no migrantes que han experimentado la ocurrencia de los eventos del curso de vida en la transición a la adultez, 2010

\begin{tabular}{lrrr}
\hline Evento transicional & No migrantes & Migrantes & Total \\
\hline Primera relación sexual & & & \\
Sí & 61.3 & 85.5 & 61.8 \\
No & 38.7 & 14.5 & 38.2 \\
& 100.0 & 100.0 & 100.0
\end{tabular}

Primer hijo(a)

Sí

No

28.0

39.5

60.5

100.0
72.0

100.0
53.3

46.7

100.0
28.3

71.7

100.0

Primer matrimonio

Sí

No

Salida de la escuela

60.0

82.5

60.5

No

40.0

17.5

39.5

100.0

100.0

100.0

Primer trabajo

Sí

70.9

91.8

71.3

No

29.1

8.2

28.7

100.0

100.0

Fuente: elaboración propia con base en la ENJ 2010

En tanto haber experimentado la primera paternidad o maternidad la diferencia entre migrantes y no migrantes es de sólo 11 puntos porcentuales. Tales diferencias nos indican que los jóvenes migrantes experimentan en una proporción más alta todas las transiciones hacia la adultez respecto a sus símiles no migrantes, lo que muestra que la migración es un componente clave en la transición a la vida adulta y que tienen un efecto importante en la vida familiar.

\section{Tabla de vida de los eventos transiciones del curso de vida}

El análisis de las tablas de vida mediante la estimación de las proporciones acumuladas de la ocurrencia de cada evento aproxima a la temporalidad 
de la iniciación sexual, el matrimonio, el nacimiento del primer hijo, la salida de la escuela y la entrada al trabajo de los jóvenes con experiencia migratoria a Estados Unidos y nos permite realizar un análisis comparado con las transiciones de los jóvenes no migrantes (Figura 1). Las edades corresponden a los valores de 25,50 y 75 por ciento de la distribución por edades de ocurrencia de los eventos.

Del total de los jóvenes migrantes, la cuarta parte ( 25 por ciento) habían abandonado el sistema educativo a la edad de 15 años, la mitad (50 por ciento) a los 17 años y tres cuartas partes ( 75 por ciento) dejaron la escuela al cumplir los 19 años. En comparación con los jóvenes no migrantes no se observan diferencias significativas según las pruebas de Log-Rank y Wilcoxon, por lo que se acepta la hipótesis de equidad de curvas de supervivencia, y no existe un efecto de tempo en la edad a la que ocurre el abandono escolar entre migrantes y no migrantes, lo cual pudiera estar relacionado con el hecho que la escuela ha dejado de ser un factor de movilidad social y un medio para acceder a mejores oportunidades de trabajo aunado al desinterés de los jóvenes por la escuela lo que acelera la deserción escolar temprana (Giorguli y Serratos, 2009) sean migrante o no.

El inicio de la vida laboral de los jóvenes migrantes es la transición que ocurre a más temprana edad, 25 por ciento de ellos había comenzado a trabajar a los 14 años y 50 por ciento a los 16 años, en tanto, 75 por ciento de los jóvenes migrantes ya había entrado al mercado de trabajo a los 18 años. Sin embargo, hay diferencias significativas por condición migratoria de acuerdo con las pruebas estadísticas aplicadas, por lo que existe un efecto tempo en la edad de ocurrencia de la transición a la vida laboral, los jóvenes migrantes comienzan a trabajar un año antes que sus pares no migrantes en los tres cuartiles. El ingreso precoz tiene un impacto sobre la calidad de la inserción laboral de los jóvenes mexicanos migrantes, Oliveira (2006: 38-39) señala que "en un contexto de escasez de empleo y desregulación de las relaciones laborales, las fuerzas de trabajo más joven está expuesta a condiciones laborales extremadamente precarias".

La iniciación sexual es un evento que le ocurre a la cuarta parte de los jóvenes migrantes a los 15 años de edad, mientras que la mitad lo experimenta a los 17 años y las tres cuartas partes a los 18 años. Además, los jóvenes migrantes tuvieron su primera relación sexual un año antes que los no migrantes siendo esta diferencia significativa según las pruebas Log-Rank y Wilcoxon, resulta claro que los jóvenes migrantes se inician sexualmente antes que los no migrantes. 


\section{Migración internacional y transiciones a la adultez en México / M. de J. ÁVILA SÁNCHEZ et al.}

Figura 1: Edad de ocurrencia de los eventos primera relación sexual, primer matrimonio, primer hijo(a), salida de la escuela, primer trabajo, salida del hogar entre los jóvenes según condición migratoria

Salida de la escuela

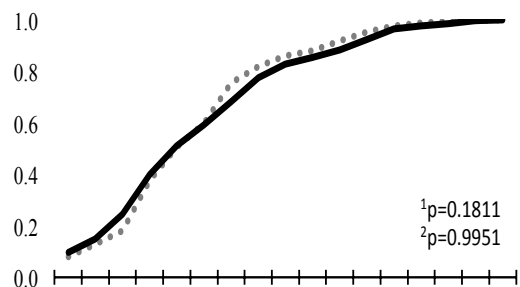

1314151617181920212223242526272829

No migrante

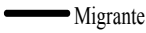

Iniciación sexual

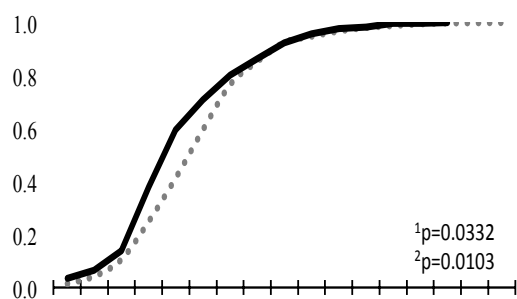

1314151617181920212223242526272829

No migrante

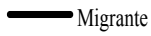

\section{Primer hijo(a)}

1.0

0.8

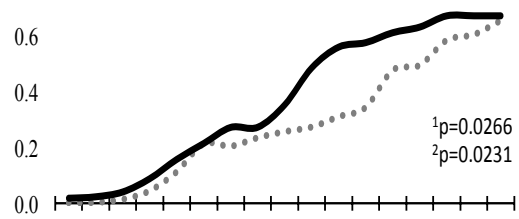

1314151617181920212223242526272829

$\cdots .$. No migrante Migrante
Primer empleo

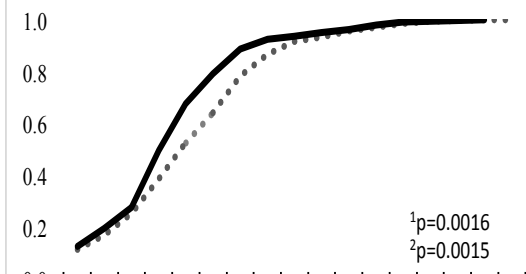

1314151617181920212223242526272829

•... No migrante $\longrightarrow$ Migrante

Primer matrimonio

1.0

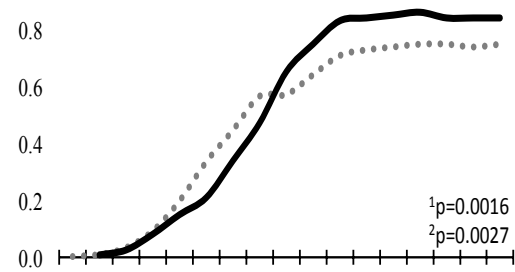

1314151617181920212223242526272829

No migrante $\longrightarrow$ Migrante

Nota: ${ }^{1} \mathrm{p}=$ Test Log-Rank; ${ }^{2} \mathrm{p}=$ Test Wilcoxon (Breslow).

Fuente: cálculos propios con base en la Encuesta Nacional de la Juventud, 2010. 
Este hallazgo concuerda con lo encontrado en otros estudios que señalan cómo la migración puede acelerar la iniciación sexual (Mberu y White, 2011; Anglewicz, VanLandingham y Phuengsamran, 2014).

Debido a que el cambio de entorno incrementa las oportunidades para que los jóvenes migrantes puedan iniciarse y participar en una gama más amplia de relaciones sexuales que las que estaban disponibles en su lugar de origen. De hecho esa mayor permisividad aumentaría la exposición a comportamientos sexuales de riesgo en estos jóvenes migrantes.

El inicio de la vida marital lo había experimentado 25 por ciento de los jóvenes migrantes a los 18 años, 50 por ciento a los 20 años y 75 por ciento de los jóvenes a los 23 años. Comparando entre los jóvenes según su condición migratoria el haber experimentado el primer matrimonio o unión en pareja, posibilita establecer cómo los migrantes entran en unión un año después que los jóvenes no migrantes en los tres cuartiles y que existe diferencia significativa en las curvas según las pruebas estadísticas realizadas. Ello es concomitante con la literatura al respecto que señala que la migración tiene un impacto negativo en el matrimonio, es decir, contribuye a retrasar el matrimonio hasta haber realizado su primera migración o acumulado los recursos económicos y bienes materiales necesarios para unirse en pareja de acuerdo con las tradiciones imperantes en su lugar de origen (Parrado, 1998 y 2011; Jampiklay, 2006; Chattopadhyay, 1999 y Pérez, 2008).

Sin embargo, llama la atención que en la gráfica 1 sobre el primer matrimonio se aprecia que a partir de los 21 años las curvas de los migrantes y no migrantes se cruzan a esta edad, indicando que hay cambios en la tendencia en la intensidad de la entrada al primer matrimonio de los migrantes, ya que el porcentaje de los que han tenido su primera experiencia matrimonial es mayor que los no migrantes. Esto estaría marcando una tendencia irregular a un ritmo de inicio de la vida conyugal que se desacelera entre migrantes en los primeros años de su juventud y se acelera luego de los 21 años, finalizando para los migrantes el tiempo de aplazamiento social para unirse en pareja y asumir obligaciones de adulto.

La entrada a la paternidad y maternidad ocurre para 25 por ciento de los jóvenes migrantes a la edad de 19 años, para 50 por ciento a la edad de 21 años y para 75 por ciento a la edad de 23 años. Este comportamiento contrasta con los jóvenes no migrantes que habían tenido su primer hijo un año antes que los migrantes en los tres cuartiles, además existe una diferencia significativa entre migrantes y no migrantes en el comportamiento de las curvas de la proporción acumulada de jóvenes que experimentaron la maternidad o paternidad. 
Se identificó que coexisten tres patrones de entrada a la paternidad o maternidad entre los jóvenes migrantes mexicanos, el primero compuesto por los que estarían experimentando la fecundidad en la etapa de la adolescencia posiblemente antes de realizar su primera migración, el segundo grupo, que es el más numeroso, estaría posponiendo la maternidad o paternidad en función de recorrer primero otras transiciones, como la unión en pareja o la migración, mientras que otros grupo de migrantes eligen no ser padres o madres en la etapa de la juventud, llegando al final del periodo de observación, 29 años, sin haber hecho la transición a la maternidad o paternidad.

\section{Interrelación entre los eventos transicionales y las características sociales}

En este apartado se analizan el impacto de las características sociales, de generación y de sexo en los patrones de evolución de los eventos transicionales de los jóvenes migrantes como: la salida de la escuela, la entrada al mercado de trabajo, la primera relación sexual, la primer unión en pareja y la primera maternidad o paternidad de los jóvenes migrantes. Estas características son percibidas en términos de desigualdades o limitaciones estructurales y culturales sobre las opciones biográficas de los jóvenes migrantes, lo que podría darle matices específicos a su proceso de transición.

Momento de la salida de la escuela de los jóvenes migrantes

Aplicando las pruebas de Log-Rank y Wilcoxon se rechaza la hipótesis de la equidad para las curvas de supervivencia por cohorte, tamaño de localidad, estrato socioeconómico y región donde residen para el caso de la salida de la escuela, y se acepta la hipótesis para el sexo por lo que las diferencias en el calendario no fueron significativas en las pruebas realizadas (con una probabilidad menor de cinco por ciento).

El calendario de la salida de la escuela varía significativamente por cohorte generacional, como se observa en la Figura 2. Así, la mitad de los jóvenes migrantes de la cohorte 1987-1998 abandonaron la escuela a los 16 años, un año antes que la generación 1981-1986. Mientras que la mitad de los jóvenes no migrantes de la cohorte 1987-1998 habían abandonado a los 20 años, un año después que la cohorte 1981-1986 que había finalizado sus estudios hasta a los 19 años. 
Figura 2: Momento de la salida de la escuela para los no migrantes y migrantes según cohorte, sexo, tipo de localidad, estrato social y región de residencia

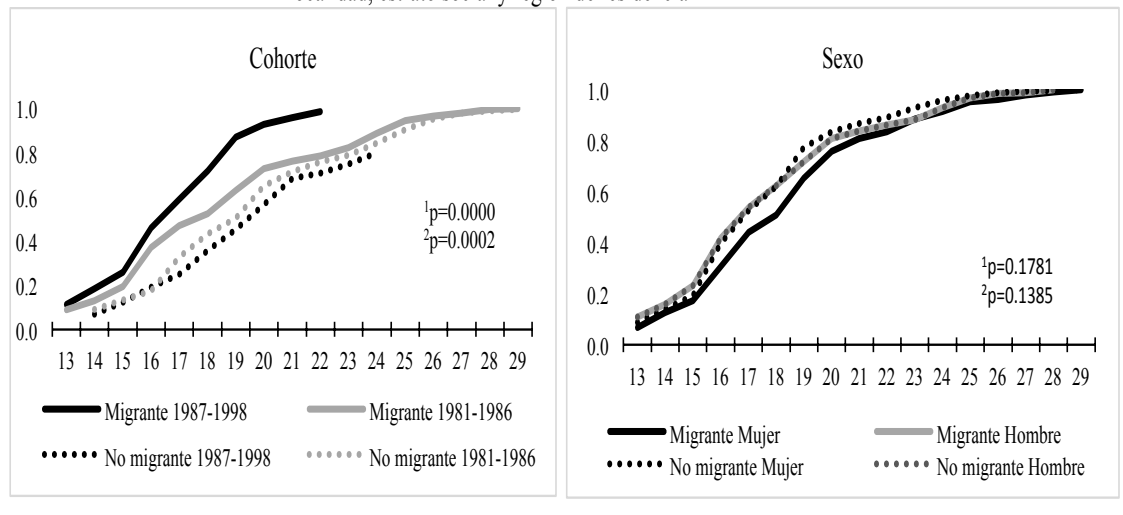

Tipo de localidad

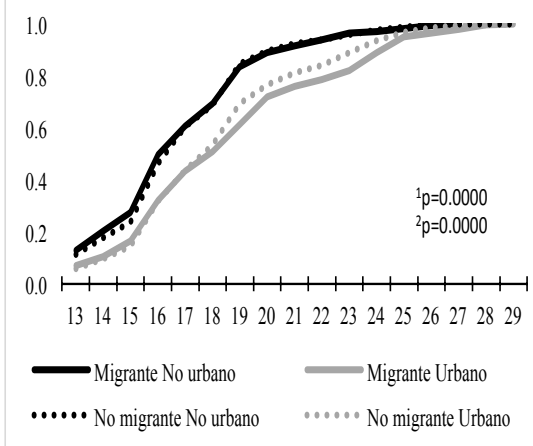

Región

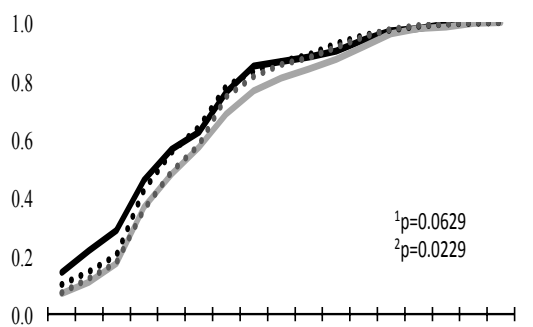

1314151617181920212223242526272829

..... Migrante Tradicional $\quad \ldots$ Migrante Resto

Nota: ${ }^{1} \mathrm{p}=$ Test $\log$-Rank; ${ }^{2} \mathrm{p}=$ Test Wilcoxon (Breslow).

Fuente: cálculos propios con base en la Encuesta Nacional de la Juventud, 2010.

\section{Estrato socioeconómico}

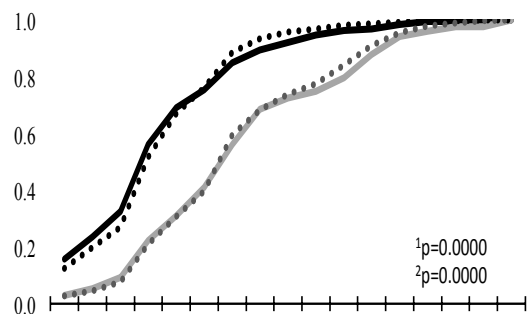

$\begin{array}{lllllllllllllllll}1 & 2 & 3 & 4 & 5 & 6 & 7 & 8 & 9 & 10 & 11 & 12 & 13 & 14 & 15 & 16 & 17\end{array}$

$\longrightarrow$ Migrante Muy bajo-Bajo $\longrightarrow$ Migrante Medio-Alto

..... No migrante Muy bajo-Bajo $\cdots . .$. No migrante Medio-Alto 
A partir de los datos se observa un calendario de abandono de la escuela formal más temprano para los jóvenes migrantes y en particular para la generación de menor edad, esto podría ser resultado de la migración a una edad más temprana, ya que se ha demostrado por Giorguli y Serratos (2009) que los jóvenes finalizan sus estudios formales antes de emigrar, ubicándolos en una situación de vulnerabilidad y rezago escolar, tendencia contraria a la observada entre los jóvenes no migrantes en donde se aprecia una postergación de la salida de la escuela entre la generación más joven.

Las diferencias en el calendario de acuerdo a la localidad de residencia, muestran que los jóvenes migrantes que habitan en espacios no urbanos abandonan la escuela un año antes que los jóvenes migrantes que residen en zonas urbanas. De acuerdo con las edades medianas, en los jóvenes no urbanos este evento se produjo a los 16 años frente a los 17 años para los jóvenes urbanos. En comparación con los jóvenes no migrantes se aprecia un patrón de comportamiento similar a los jóvenes migrantes. Por lo que más allá de la condición migratoria las diferencias observadas son resultado de las desigualdades estructurales en el acceso a la educación que persisten entre el ámbito urbano y no urbano.

En cuanto a la región de residencia de los jóvenes migrantes, se observa una pequeña diferencia entre la región tradicional y el resto del país en cuanto a la intensidad y calendario en el que ocurre el abandono escolar. Según la edad media, los jóvenes migrantes que residen en la región tradicional finalizaron su educación formal a los 16 años mientras que los que viven en el resto del país fue a los 17 años. Esto significa que los jóvenes migrantes que habitan la región tradicional experimentan la transición de la salida de la escuela a menor edad, lo que podría estar relacionado con la mayor propensión a migrar de los jóvenes que conviven con la cultura de la migración que existe en las comunidades que integran la región tradicional de migración.

En este sentido, diversos trabajos han encontrado que en familias o comunidades con mayor exposición a la migración internacional los jóvenes son menos propensos a completar las transiciones educativas que siguen a la educación pos-secundaria, para ellos la migración es más atractiva que continuar en la escuela para alcanzar vida que los jóvenes desean (Kandel, 1998; Meza y Pederzini, 2009; Halpern-Modales, 2011).

Los valores de la edad mediana de abandono escolar muestran una disparidad por estrato socioeconómico, ya que la diferencia entre los jóvenes migrantes pertenecientes al estrato muy bajo y bajo con los del estrato medio y alto es de alrededor de tres años, siendo 16 años frente a 19 años, 
respectivamente, corroborando como se esperaba, que los jóvenes migrantes de los estratos más desfavorecidos realizan esta transición más temprano que sus símiles del estrato medio y alto. Este comportamiento se corresponde al que muestran los jóvenes no migrantes, lo que pone de manifiesto que independientemente de la condición migratoria el abandono escolar a temprana edad es producto de las desigualdades socioeconómicas del hogar de origen.

\section{Momento de la entrada al mercado laboral}

Las diferencias en las pruebas Log-Rank y Wilcoxon muestran que se rechaza la hipótesis de la equidad para las curvas de supervivencia por cohorte, sexo, estrato socioeconómico, localidad y región de residencia en el caso del ingreso al mercado laboral, ya que las diferencias en función de las características estudiadas fueron significativas $(\mathrm{p}<0.05)$.

En la Figura 3, se aprecia que los jóvenes migrantes de la generación de menor edad iniciaron su vida laboral a los 15 años frente a los 16 años de los que pertenecen a la generación de mayor edad. Esto significa que los jóvenes migrantes de menor edad experimentaron la incorporación al mercado laboral más temprano, esto se relaciona con el punto anterior en donde observamos un abandono precoz de la escuela entre los jóvenes migrante de menor edad, que a su vez está asociado a una mayor precariedad del empleo al pueden acceder estos jóvenes migrantes.

Existe una brecha de dos años en la edad mediana de ingreso al mercado laboral entre los jóvenes migrantes y no migrantes. También las curvas del porcentaje acumulado muestran diferencias relevantes por sexo, tanto en intensidad como calendario, los jóvenes migrantes varones inician su vida laboral dos años antes que las mujeres migrantes (18 años y 16 años, respectivamente), corroborando como ha señalado varios autores (Mier y Teresa, 2004; Gandini y Castro, 2009) que las mujeres abandonan más temprano la escuela y entran al mercado laboral más tarde que los varones.

La entrada al mercado laboral por condición migratoria y sexo, con respecto a la edad mediana, mostró que las mujeres migrantes experimentaron esta transición un año después que las no migrantes, es decir, las mujeres migrantes muestran un mayor rezago laboral; en sentido contrario, los varones migrantes ingresaron al mercado laboral antes que sus pares. Lo que se advierte es que la condición migratoria acrecienta la brecha de género entre hombres y mujeres en la entrada al mercado laboral. 


\section{Migración internacional y transiciones a la adultez en México / M. de J. ÁVILA SÁNCHEZ et al.}

Figura 3: Momento de la entrada al mercado laboral para los no migrantes y migrantes según cohorte, sexo, tipo de localidad, estrato social y región de residencia
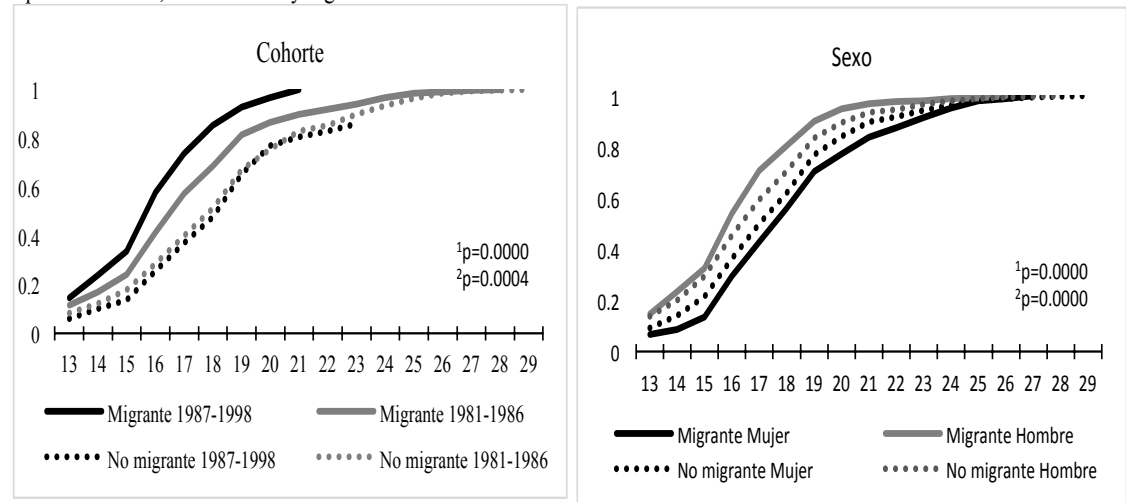

1314151617181920212223242526272829
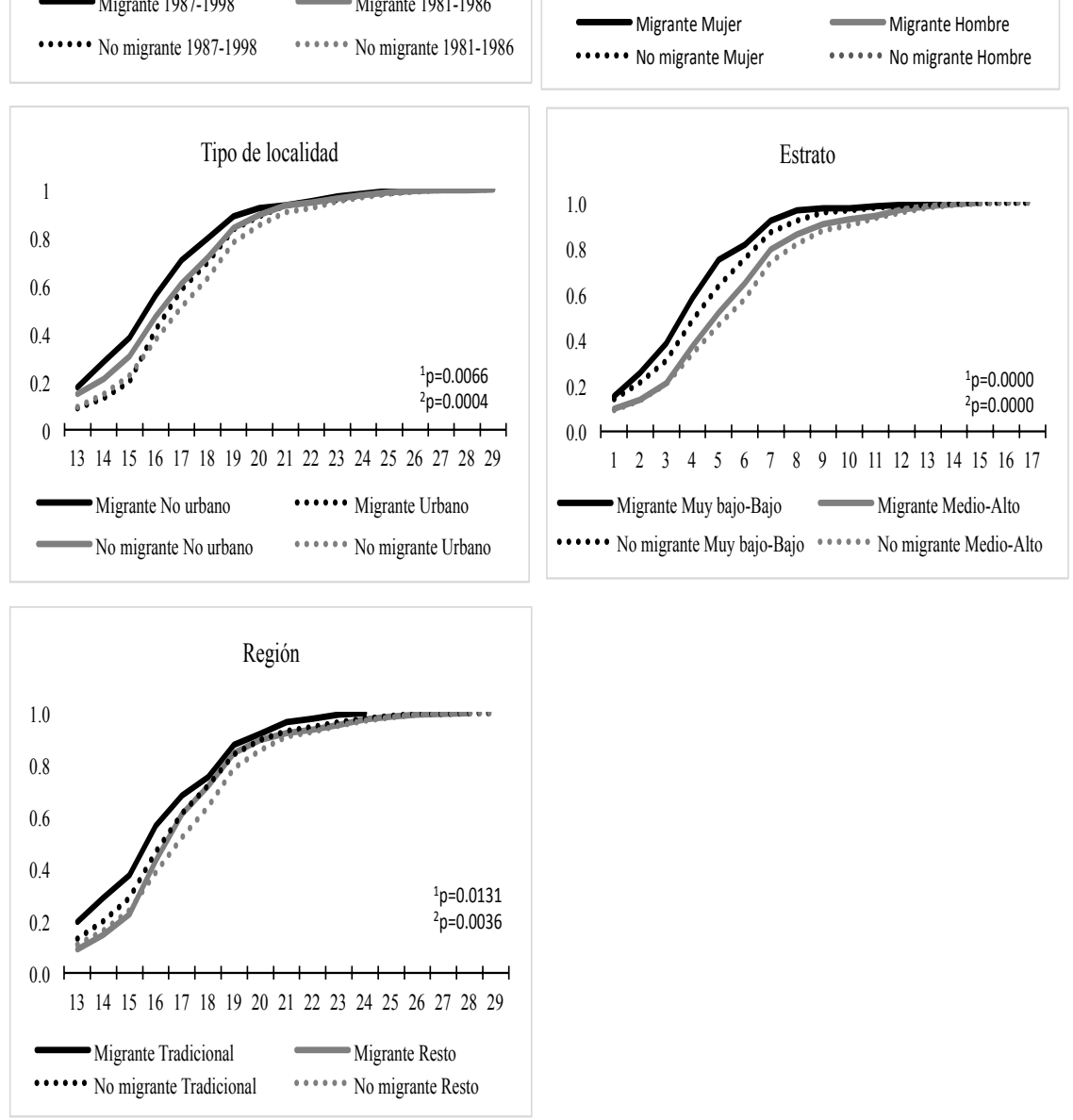

Nota: ${ }^{1} \mathrm{p}=$ Test Log-Rank; ${ }^{2} \mathrm{p}=$ Test Wilcoxon (Breslow).

Fuente: cálculos propios con base en la Encuesta Nacional de la Juventud, 2010. 
En cuanto a la localidad de residencia, los jóvenes migrantes que residen en ámbitos no urbanos ingresan al mercado laboral a una edad mediana de 15 años, un año más temprano que los residentes en zonas urbanas. Al comparar con las curvas de la proporción acumulada de los jóvenes no migrantes, se aprecia que la intensidad y el calendario de entrada al mercado laboral son mayores entre los jóvenes migrantes urbanos y no urbanos, aunque las curvas tienden a superponerse a partir de los 20 años diluyéndose las diferencias para los dos contextos.

Entre los jóvenes migrantes que residen en la región tradicional se advierte que la mayor variación ocurre antes de cumplir los 16 años, es decir, tienden a adelantar la edad de ingreso al primer empleo. La diferencia en la edad promedio fue de un año en los jóvenes migrantes de la región tradicional con respecto a los no migrantes de la misma región (16 años frente a los 17 años).

El estrato socioeconómico es la variable donde se registraron las mayores disparidades en la edad de ingreso al mercado laboral, esto entre las distintas categorías analizada correspondientes a los jóvenes. Las edades medianas muestran, que los jóvenes migrantes que pertenecen al estrato socioeconómico muy bajo y bajo ingresan dos años antes al mercado laboral que los jóvenes migrantes de los estratos medios y alto (16 años frente a 18 años).

En la comparación de los jóvenes migrantes y no migrantes del estrato muy bajo y bajo, la diferencia en la edad mediana es de un año, es decir son los jóvenes migrantes los que tienden a adelantar más esta transición, por lo que entran al mercado de trabajo antes que los jóvenes del mismo estrato social. Este hallazgo revela que la experiencia migratoria en conjunto con las desigualdades de socioeconómicas se refuerzan en detrimento de los jóvenes migrantes de escasos recursos, ya que la entrada precoz al mercado laboral es sin duda un elemento de desventaja social. Mientras que los jóvenes migrantes del estrato medio y alto inician su vida laboral casi al mismo tiempo que sus símiles no migrantes pertenecientes al mismo estrato.

\section{Momento de la primera relación sexual}

Con los resultados obtenidos de las pruebas Log-Rank y Wilcoxon se rechazan la hipótesis de la equidad de las curvas de supervivencia por cohorte y sexo, mientras que las diferencias según el tipo de localidad, región y estrato socioeconómico no fueron significativas $(\mathrm{p}<0.05)$ (Figura 4$)$. 


\section{Migración internacional y transiciones a la adultez en México / M. de J. ÁVILA SÁNCHEZ et al.}

Figura 4: Momento de la primera relación sexual para los no migrantes y migrantes según cohorte, sexo, tipo de localidad, estrato social y región de residencia
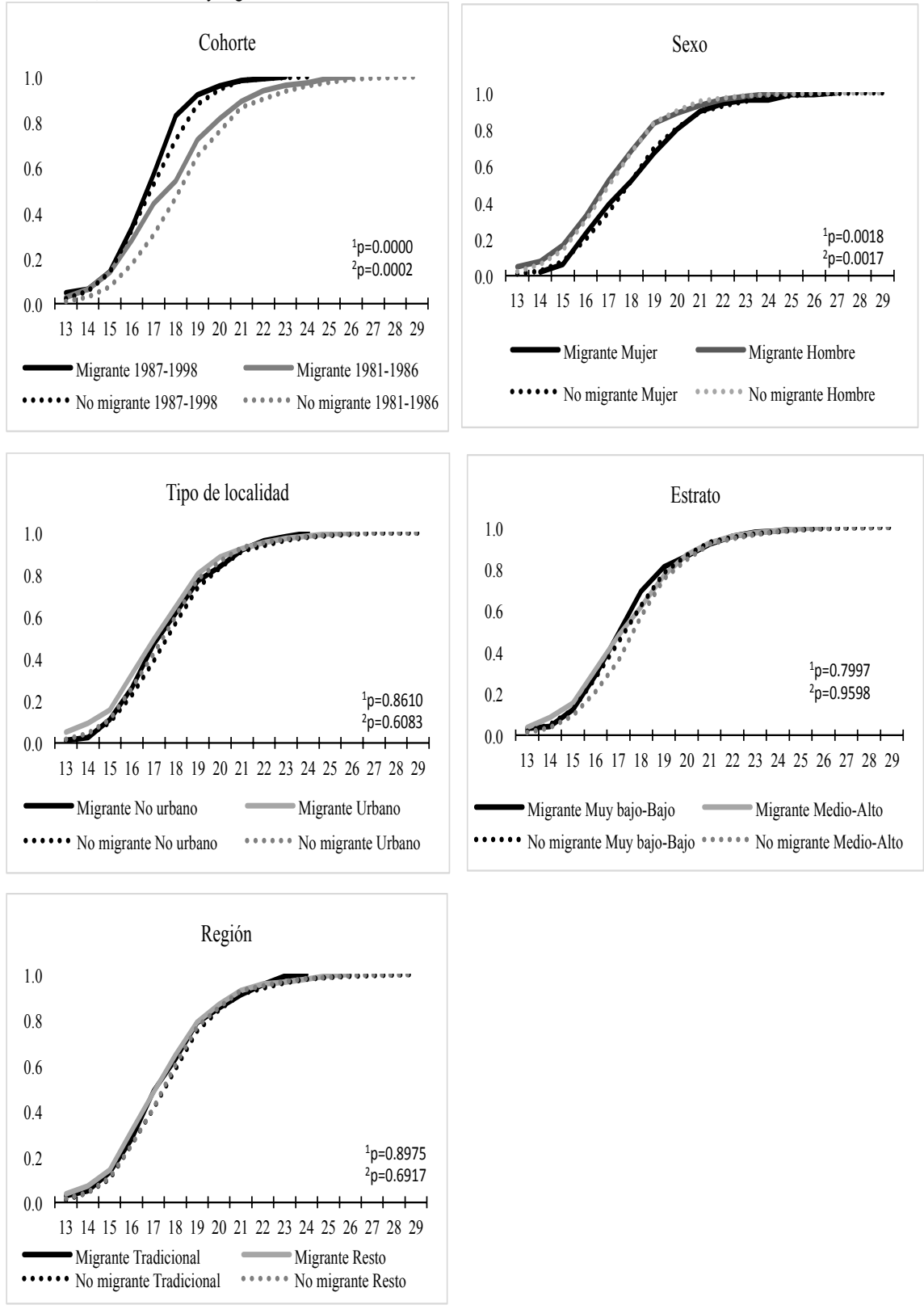

Nota: ${ }^{1} \mathrm{p}=$ Test Log-Rank, ${ }^{2} \mathrm{p}=$ Test Wilcoxon (Breslow).

Fuente: cálculos propios con base en la Encuesta Nacional de la Juventud, 2010. 
Los jóvenes migrantes de la cohorte más joven, 1987-1998, adelantaron la edad a la que tienen su primera relación sexual en un año (16 años) en relación con los pertenecientes a la cohorte de mayor edad 1981-1986 (17 años). Según la experiencia migratoria, los jóvenes migrantes de la cohorte más joven adelantaron su iniciación sexual en comparación con los jóvenes no migrantes de la misma cohorte (Figura 4). Este resultado muestra que la experiencia migratoria acelera el inicio de las experiencias sexuales, ya que el cambio a un entorno diferente proporciona una gama más amplia de oportunidades para tener relaciones sexuales en comparación con el lugar de origen (Mberu y White, 2011).

La transición a la primera relación sexual en los jóvenes migrantes muestra que la mitad de los hombres se iniciaron sexualmente un año antes que las mujeres, 17 y 18 años, respectivamente. Al comparar las curvas de la proporción acumulada de los hombres y las mujeres, no se registran mayores variaciones en el calendario de inicio de la vida sexual entre los migrantes y no migrantes. Lo que revela que la experiencia migratoria no influye en el inicio de la vida sexual de hombres y mujeres, ya que para los varones migrantes y no migrantes predomina la idea de que la actividad sexual es una demostración de virilidad y conformación de la identidad masculina.

\section{Momento de la primera unión en pareja o matrimonio}

En el caso del ingreso a la primera unión o matrimonio basados en las pruebas Log-Rank y Wilcoxon se rechaza la hipótesis de la equidad para las curvas de supervivencia por cohorte, sexo y estrato socioeconómico, además se acepta la hipótesis para la localidad y región de residencia, ya que la diferencia no fue significativa con una $\mathrm{p}<0.05$.

En Figura 5 se aprecia en los jóvenes migrantes una progresión a edades más avanzadas al momento de ingresar al primer matrimonio, en la cohorte 1987-1998 tienen un retraso de dos años (19 años) en la formación de la unión en comparación con la cohorte 1981-1986 (21 años). En la comparación de las curvas de la proporción acumulada de haber experimentado el primer matrimonio entre los migrantes y no migrantes de las dos cohortes, se observa que los jóvenes migrantes de las dos cohortes de nacimiento estudiadas transitan de manera más tardía este evento en relación con sus pares no migrantes. 


\section{Migración internacional y transiciones a la adultez en México / M. de J. ÁVILA SÁNCHEZ et al.}

Figura 5: Momento del primer matrimonio para los no migrantes y migrantes según cohorte, sexo, tipo de

localidad, estrato social y región de residencia
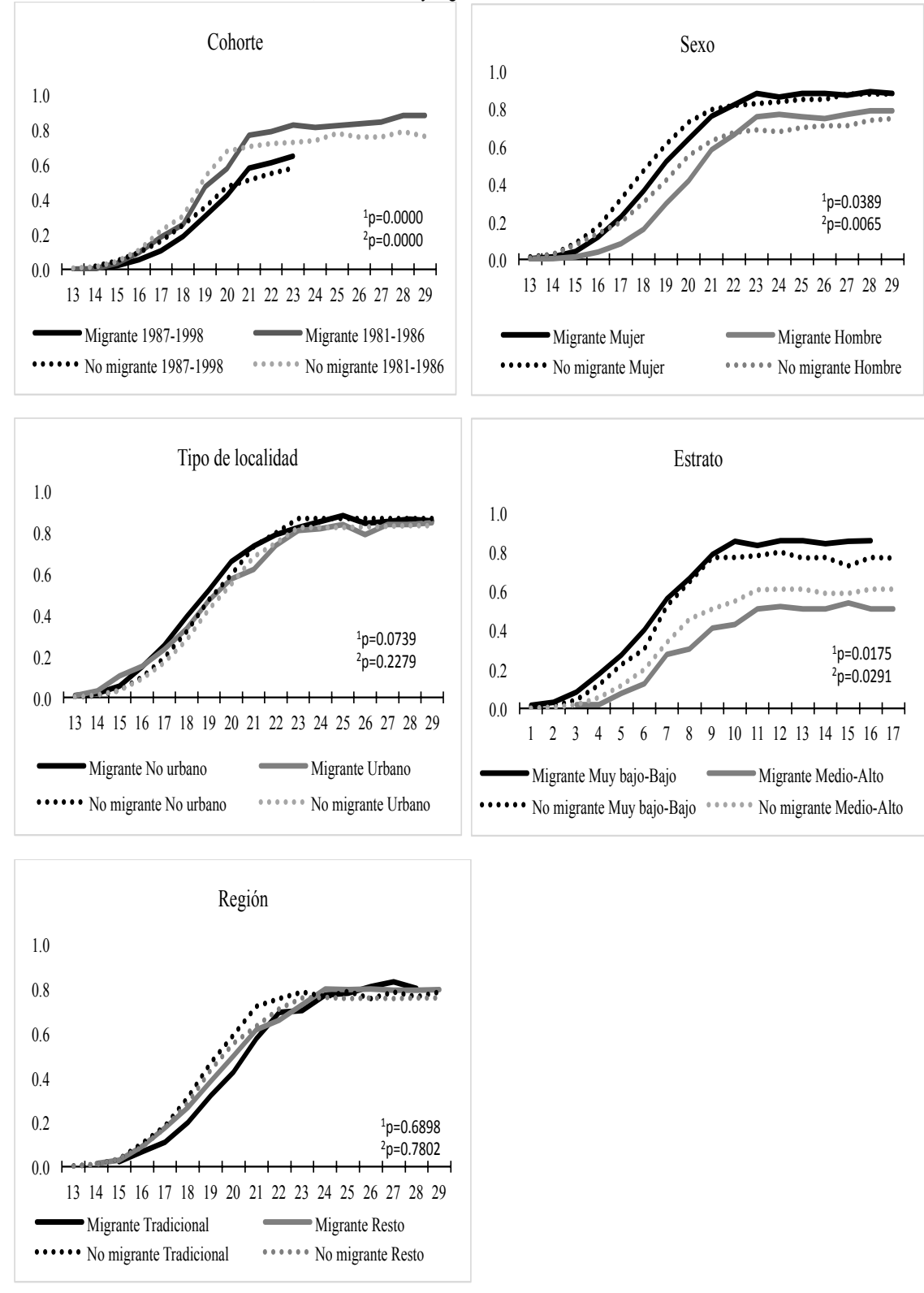

Nota: ${ }^{1} \mathrm{p}=$ Test Log-Rank; ${ }^{2} \mathrm{p}=$ Test Wilcoxon (Breslow).

Fuente: cálculos propios con base en la Encuesta Nacional de la Juventud, 2010. 
Nuestro análisis corrobora que la migración tienen un impacto negativo en el matrimonio, es decir, que la migración contribuye a retrasar el matrimonio como señalan varios estudios (Parrado, 1998; Chattopadhyay, 1999; Mier y Teran, 2004; Jampiklay, 2006), sin embargo el efecto de la experiencia migratoria es desigual según la cohorte de edad, ya que a la diferencia de las curvas entre los migrantes y no migrantes es mayor en la cohorte 1981-1986 que la registrada entre sus símiles de la cohorte 19871998.

Los migrantes presentan en la formación de la primera unión, un calendario más precoz para las mujeres que para los varones, 19 y 21 años, respectivamente. Al comparar a mujeres y varones por su experiencia migratoria se aprecia que los migrantes no siguen un patrón tradicional de nupcialidad temprana, es decir tanto las mujeres como los varones migrantes contraen matrimonio a una edad más tardía en relación con sus similares no migrantes. Aunque continúa dominando una clara diferenciación de género y una fuerte presión familiar y social para que las mujeres migrantes se unan en pareja a edades más tempranas del ciclo de vida en comparación con los varones migrantes.

En cuanto al estrato socioeconómico, se advierten grandes brechas en la transición al primer matrimonio, así, los jóvenes migrantes de los estratos menos favorecidos (muy bajo y bajo) tienen una edad mediana al primer matrimonio cuatro años menor (19 años) en comparación con los jóvenes de estratos más favorecidos (23 años). En el caso de los jóvenes migrantes de los estratos bajo y muy bajo, es posible que emprenderán su primera migración después de unirse en pareja debido a las responsabilidades económicas y familiares que han contraído.

La comparación de los jóvenes según la experiencia migratoria revela que los jóvenes migrantes de los estratos bajo y muy bajo son los que se unen en mayores proporciones y a edades más tempranas que los no migrantes del mismo estrato social. Así, los migrantes pertenecientes al estrato medio y alto experimentan un retraso en la transición al matrimonio con respecto a sus símiles no migrantes. Este resultado revela que la experiencia migratoria puede ser tanto o más fuerte que la condición socioeconómicas al momento de definir la trayectoria marital, aunque el efecto es diferencia según el estrato al que se pertenezca. Estos contrastes encontrados entre jóvenes migrantes de los diferentes estratos sociales son más acentuados que los señalados por Ariza (2005) al analizar a los jóvenes en general. 


\section{Momento del primer nacimiento}

Con los resultados obtenidos de las pruebas Log-Rank y Wilcoxon se rechaza la hipótesis de la equidad para las curvas de supervivencia por cohorte, sexo y estrato socioeconómico en lo relativo al inicio de la maternidad o paternidad, mientras que se acepta la hipótesis para el contexto y la región de residencia, ya que las diferencias en el calendario no fue significativa ( $p$ $<0.05$ ) (Figura 6).

Entre los jóvenes migrantes, las edades medianas de los miembros de la cohorte más joven (1987-1998) presentaron un retraso de dos años en la edad al momento de tener el primer hijo(a) que fue a los 22 años en comparación con los de la cohorte de mayor edad (1981-1986) que experimentaron la maternidad o paternidad a los 20 años. En relación con los no migrantes, los jóvenes migrantes pertenecientes a ambas cohortes de edad muestran una postergación de la transición al primer hijo(a), este comportamiento coincide con el retraso en la unión en pareja que se observó en el punto anterior. Por lo que se podría decir que los jóvenes con experiencia migratoria, independientemente de la cohorte a la que pertenezcan, se unen, se embarazan y tienen su primer hijo(a) más tarde que sus pares no migrantes.

De acuerdo al sexo, las mujeres migrantes experimentan una entrada a la maternidad más precoz que los hombres a la paternidad, ellas habían tenido su primer hijo a los 22 años mientras que los varones a los 24 años. Sin embargo, al comparar la proporción de la maternidad o paternidad, sin considerar si tuvieron o no experiencia migratoria, apunta en la misma dirección.

En efecto aunque las diferencias entre mujeres y hombres se mantienen pese a la experiencia migratoria, son más acentuadas entre los jóvenes migrantes donde, las mujeres migrantes experimentan el evento de tener el primer hijo(a) antes que las mujeres no migrantes, en cambio los varones migrantes experimentaron un retraso en la paternidad en comparación con sus pares. Este resultado muestra que los jóvenes con experiencia migratoria, en particular las mujeres, tienden a adherirse a una normatividad social y cultural más tradicional al momento de definir el inicio de la vida reproductiva.

La transición al primer hijo(a) de los migrantes de acuerdo al estrato social de origen revela una polarización en la intensidad de la entrada a la maternidad o paternidad. La edad media al primer hijo(a) de los migrantes pertenecientes al estrato social muy bajo y bajo es tres años menor que la de sus pares del estrato social medio y alto, 21 y 24 años, respectivamente. 
Figura 6: Momento del primer hijo(a) para los no migrantes y migrantes según cohorte, sexo, tipo de localidad, estrato social y región de residencia
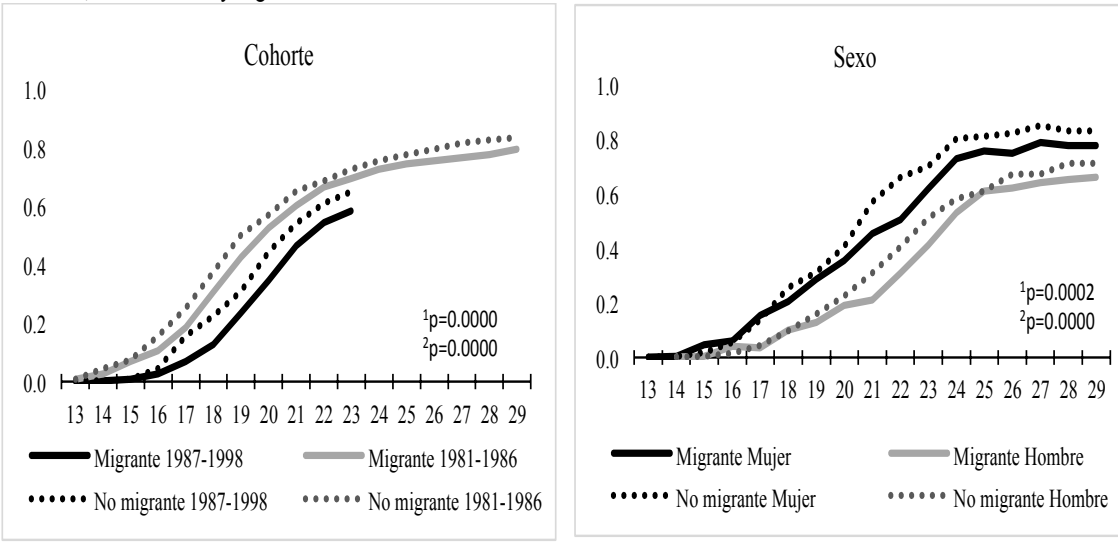

1314151617181920212223242526272829
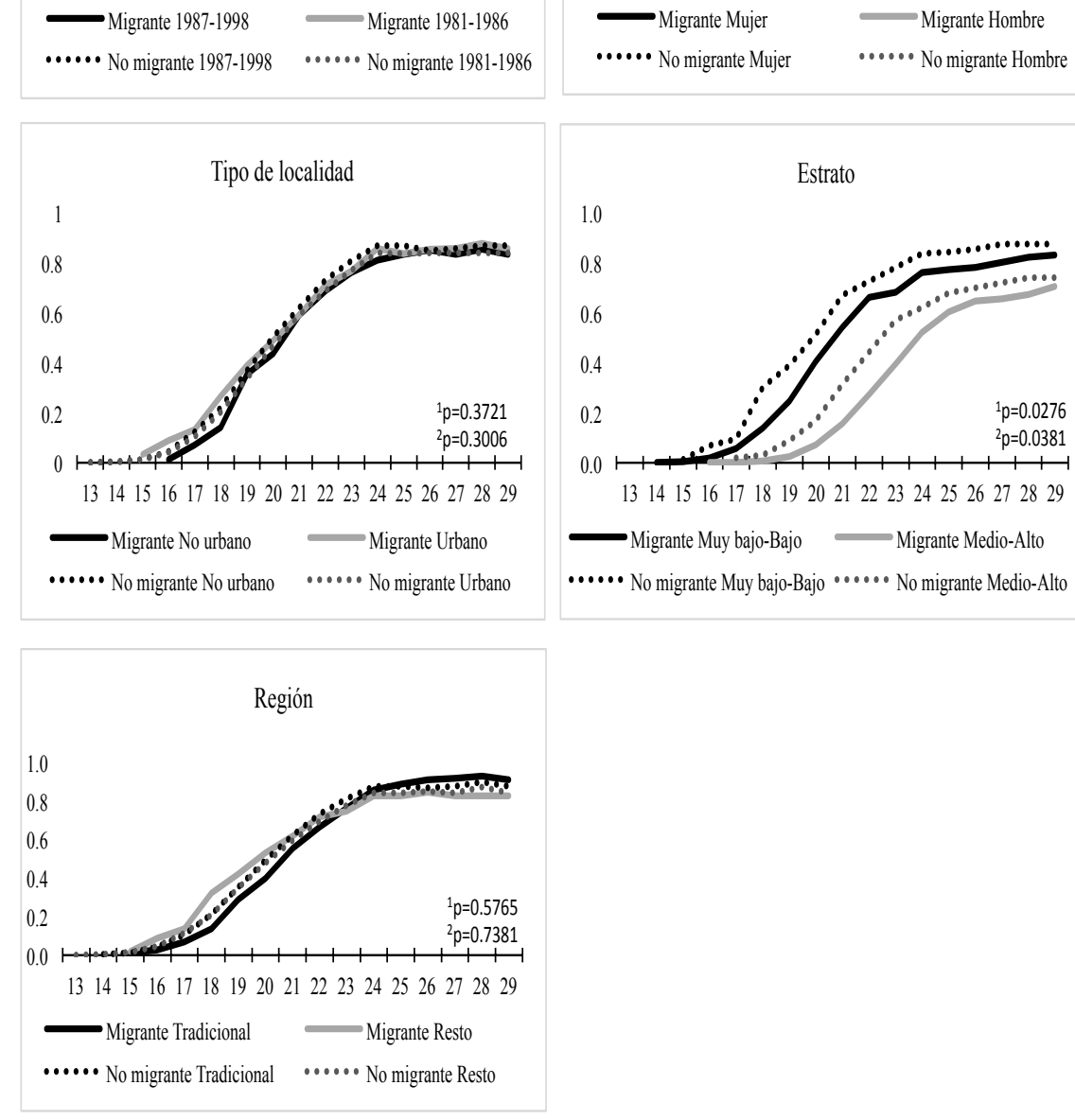

Nota: ${ }^{1} \mathrm{p}=$ Test Log-Rank, ${ }^{2} \mathrm{p}=$ Test Wilcoxon (Breslow).

Fuente: cálculos propios con base en la Encuesta Nacional de la Juventud, 2010. 
Resultados similares son proporcionados por otras autoras que señalan que los jóvenes del estrato social bajo tienen mayor probabilidad de tener su primer hijo(a) a edades más tempranas que los jóvenes de los sectores medios y altos (Mora y Oliveira, 2008).

Sin embargo, nosotros constatamos que pese a que se mantienen las diferencias entre los estratos sociales, se advierte un retraso en la transición a la maternidad o paternidad en los jóvenes con experiencia migratoria en los dos estratos sociales estudiados. Esto muestra que la experiencia migratoria puede ser más determinante o fuerte que las restricciones económicas al momento de definir la trayectoria a la maternidad o paternidad de los jóvenes migrantes.

\section{Conclusiones}

En esta investigación se presentó un análisis — event history analysis- de los patrones de transición a la adultez de los jóvenes migrantes internacionales. Este tipo de análisis permitió cuantificar la intensidad y el calendario de ocurrencia de los eventos como: la iniciación sexual, el primer matrimonio o unión en pareja, el nacimiento del primer hijo(a), la finalización de la educación formal y la entrada al mercado laboral.

Entre los hallazgos destaca que las transiciones a la edad adulta más importantes que realizan los jóvenes migrantes internacionales de acuerdo a las edades medianas son la entrada al mercado de trabajo que ocurre a los 16 años, seguida por el abandono escolar a los 17 años, casi a la misma edad sucede la iniciación sexual, tres años después comienza el inicio de la vida en pareja, a los 20 años, un año después ocurre la entrada a la paternidad o maternidad, siendo estos dos últimos eventos los menos experimentados por los jóvenes migrantes, lo que demuestra que los jóvenes migrantes siguen una secuencia transicional que no corresponde al modelo normativo.

Los resultados demuestran que la experiencia migratoria internacional tiene un efecto diferenciador y catalizador en el proceso de transición a la adultez, en particular afecta el calendario de cuatro de los cinco eventos transicionales considerados, siendo estos, la entrada al mercado laboral, la iniciación sexual, el primer matrimonio y el nacimiento del primer hijo(a), mientras que en el evento de salida de la escuela no se encontraron diferencias significativas por lo que no existe un efecto de la experiencia migratoria en la edad a la que ocurre el abandono escolar.

Los jóvenes migrantes presentan un patrón de transición a la vida adulta significativamente diferentes a los no migrantes. Los jóvenes migrantes 
tienden a adelantar su entrada al mercado laboral e iniciación sexual, mientras que tienden a posponer, tanto el matrimonio o la unión en pareja como el inicio de la paternidad o maternidad, en comparación con los no migrantes. En este sentido, la experiencia migratoria provoca un aplazamiento de las transiciones familiares (unión en pareja, embarazo y nacimiento del primer hijo(a)), debido al incremento de las políticas migratorias restrictivas aplicadas en Estados Unidos es cada vez más prolongado el tiempo que necesitan los jóvenes para hacer un ahorro y reunir las condiciones para formar una familia, lo que contribuye a explicar las transiciones familiares más tardías en los jóvenes migrantes.

Aunque al interior del grupo de los jóvenes migrantes la tendencia con la que ocurren las transiciones familiares es heterogéneo. Destaca que a partir de los 21 años los migrantes experimentan de manera más acelerada la unión en pareja, el embarazo y el nacimiento del primer hijo(a). Es decir, para los jóvenes migrantes a partir de ese momento se termina la moratoria social, por lo que deben asumir obligaciones adultas.

Se corrobora que la migración en interacción con los diferentes ejes de la desigualdad como las derivadas de la edad, género y clase social modulan diferentes trayectorias de transición a la adultez, aunque con distinta intensidad tanto al interior de los jóvenes con experiencia migratoria como con los jóvenes sin experiencia migratoria. Los migrantes más jóvenes y los que pertenecen a los estratos muy bajo y bajo son los que presentan un patrón de transición a la vida adulta más precario, ya que los migrantes más jóvenes abandonan la escuela, ingresan a trabajar e inician su vida sexual a más temprana edad que los migrantes de mayor edad. De igual forma, los jóvenes migrantes que pertenecen al estrato socioeconómico muy bajo y bajo abandonan la escuela, entran al mercado laboral, se casan, embarazan y tienen su primer hijo(a) antes que los jóvenes migrantes de los estratos medio y alto. La experiencia migratoria en conjunto con las desigualdades de socioeconómicas se refuerzan en detrimento de los migrantes más jóvenes y de escasos recursos, lo que impacta el bienestar y el desarrollo sustentable del proyecto de vida futuro de estos jóvenes.

Por último está investigación nos permite confirmar que la jóvenes migrantes constituye un grupo altamente vulnerable a la exclusión económica, social y formativa, lo que reduce las oportunidades disponibles durante sus transiciones a la edad adulta. Una tarea pendiente es examinar el significado que tiene para los jóvenes migrantes convertirse en adultos. 


\section{Migración internacional y transiciones a la adultez en México / M. de J. ÁVILA SÁNCHEZ et al.}

\section{REFERENCIAS BIBLIOGRÁFICAS}

Allison, P. D., 1982, "Discrete-time methods for the analysis of event histories", in Sociological Methodology, 13, 61-98.

Anglewicz, P., Gourvenec, D., Halldorsdottir, I., O’kane, C., Koketso, O., Gorgens, M., y Kasper, T., 2013, "The effect of interview method on self-reported sexual behavior and perceptions of community norms in Botswana", in AIDS Behav, 17(2), 674-687.

Araiza, M., 2005, “Juventud, migración y curso de vida. Sentidos y vivencias de la migración entre los jóvenes urbanos mexicanos", en Mier y Terán, Marta y Rabell, Cecilia (coords.) Jóvenes y niños: Un enfoque sociodemográfico, pp. 39-70, México. FLACSO.

Ávila, M. J. y Jáuregui, J. A., 2014, “Iniciación sexual, unión en pareja y nacimiento del primer hijos de los jóvenes en Chiapas, 2010", en Cavenaghi, Suzana y Cabella, Wanda (coords.). Comportamiento reproductivo y fecundidad en América Latina: una agenda inconclusa (pp. 207-229). UNFPA y ALAP.

Beck, U., 1998, La sociedad del riesgo: Hacia una nueva modernidad. Barcelona: Editorial Paidós.

Bourdieu, P., 1997, Razones prácticas. Sobre la teoría de la acción. Barcelona: Anagrama.

Coubès, M. L. y Zenteno, R., 2005, “Transición hacia la vida adulta en el contexto mexicano: una discusión a partir del modelo normativo", en Coubès, Marie-Laure, Zavala de Cosío, María Eugenia y Zenteno, René (coords.). Cambio demográfico y social en el México del siglo XX: una perspectiva de historias de vida, pp. 331352, México. El Colegio de la Frontera Norte.

Chattopadhyay, A., 1999, Marriage and Migration in the Changing Socioeconomic Context of Nang Rong, Thailand. Paper presented at the annual meeting of the Population Association of America. New York. Marzo 25-27.

Echarri, C. y Pérez-Amador, J., 2004, "El tránsito hacia la adultez: eventos en el curso de vida de los jóvenes en México", in Estudios Demográficos y Urbanos, 22 (1), 44-77.

Fan, C. C. y Huang, Y., 1998, "Waves of rural brides: female marriage migration in China", in Annals of the Association of American Geography, 88(2), 227-251.

Gandini, L. y Castro, N., 2006, La salida de la escuela y la incorporación al mercado de trabajo en los años de juventud. Análisis de tres cohortes de hombres y mujeres en México. Ponencia presentada en el Seminario La dinámica demográfica y su impacto en el mercado laboral de los jóvenes, UAM, 28 de noviembre, México.

Giorguli, S. E. y Serratos, I., 2009, “El impacto de la migración internacional sobre la asistencia escolar, ¿paradojas de la migración?”, en Leite, Paula y Giorguli, Silvia, (Coords.) El estado de la migración, pp. 313-344, México. Consejo Nacional de Población. 
Hobsbawm, E., 2001, Historia del siglo XX. Barcelona: Crítica.

Hogan, D. y Astone, N., 1986, "The transition to adulthood", in Annual Review of Sociology, 12, 109-130.

Hosmer, D., Lemeshow, S. y May, S., 1999, Applied survival analysis: regression modeling of time to event data. New York. John Wiley and Sons, Inc.

Jampaklay, A., 2006, "How does leaving home affect marital timing? An event-history analysis of migration and marriage in Nang Rong, Thailand", in Demography, 43(4) 711-725.

Kandel, W. y Massey, D., 2002, "The Culture of Mexican Migration: A Theoretical and Empirical Analysis", in Social Forces, 80(3), 981-1004.

Konietzka, D. y Huinink, J., 2003, "Die De-StandardisierungeinerStatuspassage? ZumWandel des Auszugsausdem Elternhaus und des Übergangs in das Erwachsenenalter in Westdeutschland”, in Soziale Welt, 54 (3), 285-311.

Lindstrom, D. y Giorguli, S., 2007, "The Interrelationship between Fertility, Family Maintenance, and Mexico-U.S. Migration", in Demographic Research Review, 17(28), 821-858.

Mberu, B. y White, M., 2011, "Internal migration and health: Premarital sexual initiation in Nigeria", in Social Science \& Medicine, 72(8), 1284-1293.

Mier y Terán, M., 2004, "Pobreza y transiciones familiares a la vida adulta en las localidades rurales de la península de Yucatán”, en Población y salud en Mesoamérica, vol. 2, núm. 1.

Montiel, G., 2009, "Transiciones virtuales en la juventud: una aproximación a la emancipación juvenil en la sociedad de la información", en RECERCA, Revista de Pensament i Anàlisi, 9, 145-170.

Mora, M. y Oliveira, O de, 2008, "Desigualdades sociales y transición a la adultez en el México contemporáneo”, en Papeles de Población, 14(57), 117-152.

Mussino, E. y Strozza, S., 2012, "The fertility of immigrants after arrival: The Italian case", en Demographic Research, 26 (4), 99-130.

Oliveira, O de, 2006, "Jóvenes y precariedad laboral en México", en Papeles de Población, 12(), 37-73.

Parrado, E., 1998, Marriage and International Migration: Timing and Ordering of Life Course Transitions Among Men in Western Mexico. Paper presented at the Seminar Men, Family Formation and Reproduction, IUSSP/CENEP, Buenos Aires.

Parrado, E., 2011, "How High is Hispanic/Mexican Fertility in the United States? Immigration and Tempo Considerations", en Demography, 48(3), 1059-1080.

Pérez Amador, J., 2008, “Análisis multiestado multivariado de la formación y disolución de las parejas conyugales en México", en Estudios Demográficos y Urbanos, 23(3), 481-511. 
Petersen, T., 1991, The Statistical Analysis of Event Histories. Sociological Methods and Research, 19 (3), 270-323.

Wilson, B. y Sigle-Rushton, W., 2014, A conceptual framework for migrant fertility. Paper presented at the European Population Conference, Budapest, Hungary, Junio 25-28.

\section{RESUMEN CURRICULAR DE LOS AUTORES}

\section{María de Jesús Ávila Sánchez}

Es Licenciada en Sociología por la Universidad Autónoma de Aguascalientes, Maestra en Demografía por el Colegio de la Frontera Norte y Doctora en Ciencias Sociales por la Universidad de Leiden en los Países Bajos, Holanda. Actualmente se desempeña como Profesora Investigadora en el Instituto de Investigaciones Sociales de la Universidad Autónoma de Nuevo León, México. Miembro de Sistema Nacional de Investigadores Nivel I (SNI-1) que concede el CONACYT y cuenta con el Perfil del Programa de Mejoramiento del Profesorado (PROMEP) otorgado por la SEP. Ha publicado diversos artículos en revistas arbitradas. Sus líneas de investigación son el análisis demográfico de los jóvenes, migración interna e internacional, con énfasis en la inmigración de centroamericanos en frontera sur de México y el desarrollo sustentable.

Dirección electrónica: marycolef@yahoo.com

\section{José Alfredo Jáuregui Díaz}

Es Licenciado en Sociología por la Universidad Autónoma de Aguascalientes, Maestro en Demografía por el Colegio de la Frontera Norte y Doctor en Demografía en el Centre d'EstudisDemogràfics de la Universidad Autónoma de Barcelona. En el sector público ha trabajado como asesor en los Consejos Estatales de Población de Quintana Roo y Chiapas. Actualmente es Profesor Investigador en el Instituto de Investigaciones Sociales de la Universidad Autónoma de Nuevo León, México. Miembro de Sistema Nacional de Investigadores Nivel I (SNI-1) que concede el CONACYT y cuenta con el Perfil del Programa de Mejoramiento del Profesorado (PROMEP) otorgado por la SEP. Tiene diversas publicaciones sobre migración y marginación en revistas arbitradas. Sus líneas de investigación son migración interna e internacional, dinámica sociodemográfica y desarrollo sustentable.

Dirección electrónica: alfjadi@yahoo.com.mx 


\section{Karina Pizarro Hernández}

Es Doctora en Ciencias Antropológicas y Profesora-investigadora del Área Académica de Sociología y Demografía del Instituto de Ciencias Sociales y Humanidades de la Universidad Autónoma del Estado de Hidalgo. Sus líneas de investigación son migración transnacional y cultura e identidad. Miembro de Sistema Nacional de Investigadores Nivel I (SNI-1) que concede el CONACYT y cuenta con el Perfil del Programa de Mejoramiento del Profesorado (PROMEP) otorgado por la SEP. Líder del Cuerpo Académico Problemas Sociales de la Modernidad. Autora del libro El pasaporte, la maleta y la barbacoa. La experiencia urbana a través de los saberes y sabores transnacionales Pachuca-Chicago. Así mismo ha publicado varios artículos sobre el tema de migración, identidad y género.

Dirección electrónica: kapiher@hotmail.com 